splitting is pronounced. Subtle differences exist between published LEED patterns, and it was observed (10) that beam splitting had some beam energy dependence.

Finally, it should be mentioned that careful X-ray measurements (30) have indicated an outward relaxation of the interplanar spacings of surface layers of $\sim 4$ per cent for gold $\{111\}$. These measurements were performed on air contaminated surfaces, and confirmation of such an effect must await LEED or RHEED data (and adequate theory) from surfaces prepared in ultra high vacuum. There is obviously a great deal of basic research yet to be performed on "clean" gold surfaces.

\section{References}

1 E. Bauer, "Techniques of Metals Research", Vol. 2, Ch. 16, Ed. Bunshah, (1969) Wiley

2 M. Prutton, Met. Rev., 1971, 16, 57

3. P. J. Estrup and E. G. McRae, Surface Sci., 1971, 25,1

4 E. Bauer, "Techniques of Metals Research", Vol. 2, Ch. 15, Ed. Bunshah, (1969) Wiley

5 C. C. Chang, Surface Sci., 1971, 25, 53

6 P. W. Palmberg, "Electron Spectroscopy", North Holland, Ed. Shirley, (1972), p. 835

7 D. G. Fedak and N. A. Gjostein, Phys. Rev. Lett., 1966, 16, 171

8 D. G. Fedak and N. A. Gjostein, Acta Met., 1967, 15, 827

9 E. A. Wood, F. Appl. Phys., 1964, 35, 1306
10 D. G. Fedak and N. A. Gjostein, Surface Sci., 1967, 8, 77

11 G. E. Rhead, F. Phys. F. Metal Phys., 1973, 3, L53

12 D. G. Fedak, J. V. Florio, W. D. Robertson, "The Structure and Chemistry of Solid Surfaces", Ed. G. A. Somorjai (1969), Wiley, p. 74-1

13 A. M. Mattera, R. M. Goodman and G. A. Somorjai, Surface Sci., 1967, 7, 26

14 P. W. Pal mberg and T. N. Rhodin, Phys. Rev., 1967, 161,586

15 P. W. Palmberg and T. N. Rhodin, 7. Chem. Phys., $1968,49,134$

16 E. Bauer, A. K. Green and K. M. Kunz, Appl. Phys. Lett., 1966, 8, 248

17 E. Bauer, "Structure et Propriétés des Surfaces des Solides", Paris (1969), p. 111

18 P. N. J. Dennis and P. J. Dobson, Surface Sci, 1972, 43, 3919

19 F. Grønlund and P. E. Højlund-Nielsen, f. Appl. Phys, 1972, 43, 3919

20 J. P. Biberian and G. E. Rhead, F. Phys. F. Metal Phys., 1973, 3, 675

21 S. Hagstrom, H. B. Lyon and G. A. Somorjai, Phys. Rev. Lett., 1965, 15, 491

22 J. T. Grant, Surface Sci., 1969, 18, 228

23 W. A. Fraser, J. V. Florio, W. N. Delgass and W. D. Robertson, Surface Sci., 1973, 36, 661

24 H. H. Brongersma and P. M. Mul, Surface Sci., 1973, 35, 393

25 A. Benninghoven, Surface Sci., 1973, 35, 427

26 L. E. Murr, Thin Solid Films, 1969, 4, 389 and Scripta Met., 1972, 6, 203

27 P. E. Højlund-Nielsen, Surface Sci., 1973, 36, 778

28 R. W. Joyner, submitted to Surface Sci.

29 A. E. Morgan and G. A. Somorjai, Surface Sci., 1968, 12, 405

30. R. W. Vook, S. Ouyang and M. A. Otooni, Surface Sci, $1972,29,277$

\title{
Ordering in Gold-Copper Alloys
}

\section{A STUDY BY THERMOPOWER MEASUREMENT}

It is only comparatively recently that the parameters upon which depends the absolute thermopower of a metal have been fully understood and it is for this reason that thermopower measurement has not hitherto been extensively utilised as a metallurgical tool. R. D. Barnard and A. J. M. Chivers of the University of Salford now suggest, however, that in certain circumstances the measurement of thermopower can provide a more sensitive alternative to the ubiquitous resistivity method for studying phase transitions and ordering processes in metals and alloys, and have applied it specifically to a study of the ordering kinetics of $\mathrm{CuAu}$ and $\mathrm{Au}_{3} \mathrm{Cu}$ (Metal Sci. F., 1973, 7, (July), 147-152). These are apt choices inasmuch as CuAu possesses two ordered phases both of which have resistivities lower than that of the disordered phase, while $\mathrm{Au}_{3} \mathrm{Cu}$ is anomalous in that it has a slightly higher resistivity in the ordered state. It is in this sort of situation that the resistivity method of studying phase changes has such obvious limitation.

The total thermoelectric power of metals and alloys is usually dominated by the diffusion component, $\mathrm{S}_{\mathrm{D}}$, which is a bulk property of any metal and whose value is of prime interest in this context for reasons which will become apparent.

Measurements were made using a simple thermocouple arrangement whereby the sample material and a reference metal were subjected to a temperature gradient. The Seebeck e.m.f., $\varepsilon$, thus produced is related to the absolute thermopower by the equation $d \varepsilon / d \mathrm{~T}=\mathrm{S}_{\mathrm{D} \text { (sample) }}-\mathrm{S}_{\mathrm{D} \text { (ref) }}$. It is clear, therefore, that provided $S_{D}($ (re) $)$ is a monotonic function of temperature, then changes in $\varepsilon$ can give a direct insight of the structural changes taking place in the sample. It is obviously desirable that the sample be kept in a virtually isothermal environment, - but to generate a measurable e.m.f. of even a few microvolts a small temperature gradient must be established.

With this in mind apparatus was constructed which permitted thermal e.m.f. measurement while enabling the temperature of the sample to be controlled, especially with respect to means of reducing the sample temperature to a stable level below the transition temperature as quickly as possible.

Samples were made up in the form of wire. With $\mathrm{Au}_{3} \mathrm{Cu}$ a conventional drawing process was employed but with $\mathrm{CuAu}$ it was necessary to cast the wire in a fine quartz tube.

Results obtained by this method are very encouraging, particularly for $\mathrm{Au}_{3} \mathrm{Cu}$ for which evidence came to light for the occurrence of short range ordering at temperatures considerably higher than those previously reported, as well as the existence of fine structure in the ordering curve. $\quad$ A. D. M. K. 